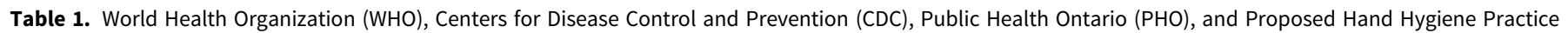
Recommendations

\begin{tabular}{|c|c|c|c|}
\hline $\begin{array}{l}\text { WHO Five Moments } \\
\text { for Hand Hygiene }\end{array}$ & $\begin{array}{c}\text { CDC HICPAC Recommendations for Hand Hygiene } \\
\text { in Healthcare Settings }\end{array}$ & $\begin{array}{l}\text { PHO Your Four Moments for } \\
\text { Hand Hygiene }\end{array}$ & $\begin{array}{l}\text { Proposed } \\
\text { Revisions }\end{array}$ \\
\hline $\begin{array}{l}\text { Before touching a } \\
\text { patient }\end{array}$ & Immediately before touching a patient & $\begin{array}{l}\text { Before initial patient or } \\
\text { patient environment contact }\end{array}$ & $\begin{array}{l}\text { Before patient or patient environment contact, } \\
\text { including entering the patient's care area }\end{array}$ \\
\hline $\begin{array}{l}\text { Before clean/aseptic } \\
\text { procedure }\end{array}$ & $\begin{array}{l}\text { Before performing an aseptic task or handling } \\
\text { invasive medical devices }\end{array}$ & Before aseptic procedure & $\begin{array}{l}\text { Before clean or aseptic procedure and donning } \\
\text { gloves }\end{array}$ \\
\hline $\begin{array}{l}\text { After body fluid } \\
\text { exposure risk }\end{array}$ & $\begin{array}{l}\text { Before moving from work on a soiled body site } \\
\text { to a clean body site on the same patient }\end{array}$ & After body fluid exposure risk & After body fluid exposure risk and doffing gloves \\
\hline $\begin{array}{l}\text { After touching a } \\
\text { patient }\end{array}$ & $\begin{array}{l}\text { After touching a patient or the patient's } \\
\text { immediate environment }\end{array}$ & $\begin{array}{l}\text { After patient or patient } \\
\text { environment contact }\end{array}$ & $\begin{array}{l}\text { After patient or patient environment contact, } \\
\text { including exiting the patient's care area }\end{array}$ \\
\hline \multirow[t]{2}{*}{$\begin{array}{l}\text { After touching } \\
\text { patient surroundings }\end{array}$} & $\begin{array}{l}\text { After contact with blood, body fluids, or } \\
\text { contaminated surfaces }\end{array}$ & & \\
\hline & Immediately after glove removal & & \\
\hline
\end{tabular}

infections. Additional benefits, such as improved patient satisfaction or perception, and alignment with existing auditing programs, may also result.

\section{Acknowledgments.}

Financial support. No financial support was provided relevant to this article.

Conflicts of interest. All authors report no conflicts of interest relevant to this article.

\section{References}

1. Five moments for hand hygiene. World Health Organization website. https:// www.who.int/gpsc/tools/Five_moments/en/. Accessed April 9, 2021.

2. Hand hygiene in healthcare settings. Centers for Disease Control and Prevention website. https://www.cdc.gov/handhygiene/providers/guide line.html. Accessed April 9, 2021.

3. Just clean your hands - hospitals. Public Health Ontario website. https://www. publichealthontario.ca/en/health-topics/infection-prevention-control/handhygiene/jcyh-hospitals. Accessed April 9, 2021.

4. Sax H, Allegranzi B, Uckay I, Larson E, Boyce J, Pittet D. 'My five moments for hand hygiene': a user-centered design approach to understand, train, monitor and report hand hygiene. J Hosp Infect 2007;67:9-21.
5. Cohen B, Hyman S, Rosenberg L, Larson E. Frequency of patient contact with health care personnel and visitors: implications for infection prevention. Jt Comm J Qual Patient Saf 2012;38:560-565.

6. Boyce JM, Potter-Bynoe G, Chenevert C, King T. Environmental contamination due to methicillin-resistant Staphylococcus aureus: possible infection control implications. Infect Control Hosp Epidemiol 1997;18: 622-627.

7. Chia PY, Sengupta S, Kukreja A, Ponnampalavanar SSL, Ng OT, Marimuthu K. The role of hospital environment in transmissions of multidrug-resistant gram-negative organisms. Antimicrob Resist Infect Control 2020;9:29.

8. Gon G, Dancer S, Dreibelbis R, Graham WJ, Kilpatrick C. Reducing hand recontamination of healthcare workers during COVID-19. Infect Control Hosp Epidemiol 2020;41:870-871.

9. Fuller C, Savage J, Besser S, et al. "The dirty hand in the latex glove": a study of hand hygiene compliance when gloves are worn. Infect Control Hosp Epidemiol 2011;32:1194-1199.

10. Chang NCN, Reisinger HS, Schweizer ML, et al. Hand hygiene compliance at critical points of care. Clin Infect Dis 2021;72:814-820.

11. Michaelsen K, Sanders JL, Zimmer SM, Bump GM. Overcoming patient barriers to discussing physician hand hygiene: do patients prefer electronic reminders to other methods? Infect Control Hosp Epidemiol 2013;34: 929-934.

\title{
In vitro comparison of 3 different brushes for manual cleaning of endoscopes
}

\author{
Sofie Colman $\mathrm{MD}^{1}$ (1), Thomas Vanzieleghem $\mathrm{PhD}^{2}$ and Isabel Leroux-Roels MD, $\mathrm{PhD}^{1,3}$ \\ ${ }^{1}$ Department of Laboratory Medicine, Ghent University Hospital, Ghent, Belgium, ${ }^{2}$ Ion Beam Applications, Louvain La Neuve, Belgium and ${ }^{3}$ Infection Control \\ Team, Ghent University Hospital, Ghent, Belgium
}

To the Editor-Flexible endoscopes may become heavily contaminated with blood, secretions, and microorganisms during use. Over the last several years an increasing number of cases have been

\section{Author for correspondence: Sofie Colman, E-mail: colmansofie@gmail.com}

Cite this article: Colman S, Vanzieleghem T, and Leroux-Roels I. (2022). In vitro comparison of 3 different brushes for manual cleaning of endoscopes. Infection Control \& Hospital Epidemiology, 43: 1076-1078, https://doi.org/10.1017/ice.2021.170 reported in which patients have been exposed to infectious microorganisms by contaminated gastrointestinal (GI) endoscopes. ${ }^{1}$

The complete and accurate reprocessing of flexible endoscopes is a multistep procedure involving manual cleaning followed by high-level disinfection (HLD) and active drying before storage. ${ }^{2}$ Because almost all reported outbreaks are related to breaches in reprocessing techniques, it is crucial that endoscope cleaning, disinfection, and drying are performed according to a strict protocol. 
Table 1. Mean ATP Results and Culture Yield After Different Brushing Techniques Performed on an Endoscope Model ${ }^{a}$

\begin{tabular}{|c|c|c|c|c|c|c|}
\hline \multirow[b]{2}{*}{ Variable } & \multicolumn{3}{|c|}{ Type of Brush } & \multicolumn{3}{|c|}{ Controls } \\
\hline & PULL TRHU & Push\&Pull & DCB & Negative & Positive $^{b}$ & Positive $^{c}$ \\
\hline Mean ATP value (RLU) ( $\pm S D)$ (range) & $\begin{array}{c}13.9( \pm 13.7) \\
(0-30)\end{array}$ & $\begin{array}{c}1.0( \pm 0.6) \\
(0.5-2)\end{array}$ & $\begin{array}{c}80.3( \pm 89.9) \\
(20-233)\end{array}$ & $0(0-0)$ & $\begin{array}{c}3,274 \\
(758-6,395)\end{array}$ & $\begin{array}{c}65 \\
(35-82)\end{array}$ \\
\hline Mean yield of culture (CFU/100 mL) ( \pm SD) (range) & $\begin{array}{c}1.4( \pm 1.7) \\
(0-4)\end{array}$ & $\begin{array}{c}0.6( \pm 1.3) \\
(0-3)\end{array}$ & $\begin{array}{l}2( \pm 1) \\
(1-3)\end{array}$ & 0 & 175 & 12 \\
\hline Correlation coefficient (rs) and $P$ value ${ }^{d}$ & $\begin{array}{c}-0.872 \\
(P=.054)\end{array}$ & $\begin{array}{c}-0.559 \\
(P=.327)\end{array}$ & $\begin{array}{c}0.632 \\
(P=.252\end{array}$ & NA & NA & NA \\
\hline Log10 reduction of ATP due to brushing $( \pm S D)^{e}$ & $-2.75( \pm 0.71)$ & $-3.58( \pm 0.23)$ & $-1.81( \pm 0.71)$ & NA & NA & NA \\
\hline Recovery (\%) CFU/100 mL relative to positive control & 0.8 & 0.3 & 1.1 & NA & NA & NA \\
\hline
\end{tabular}

Note. RLU, relative light units; SD, standard deviation; NA, not applicable.

a In a pairwise comparison of the ATP values (Kruskall-Wallis test $P<.05$ was considered statistically significant) only the difference between the Push\&Pull and DCB subgroups was retained as statistically significant $(P=.009)$.

bTwo positive control tubes were not submerged in the water and not brushed.

'Two positive control tubes were submerged in water and flushed with water but not brushed.

${ }^{\mathrm{d}}$ Correlation between mean ATP value and mean yield of culture (Spearman correlation coefficient)

e Log10 reduction of ATP caused by brushing was calculated as log10 reduction of mean ATP value of the brushed PTFE tubes to the positive controls not flushed with water and not brushed.

Manual cleaning is a critical reprocessing step, removing $>99 \%$ of the bioburden from the endoscope prior to automated reprocessing. ${ }^{3}$ Several different types of brushes are used as an essential accessory to routine manual cleaning, but very little is known about the differences in the performance of these brushes. Therefore, we compared the performance of different brushes widely used for manual cleaning of flexible endoscopes: (1) a PULL THRU brush (Medivators, Minneapolis, MN), (2) Push\&Pull brush (with sweeper) (Endoss, The Netherlands), and (3) a double-cleaning brush (DCB; Nova LightSystems, France).

For the endoscope model, we used new polytetrafluoroethylene (PTFE) tubes soiled with a pool of 4 positive hemocultures. The method was based on the method described by Cattoir et $\mathrm{al}^{4}{ }^{4}$ and detailed method description can be found in the Supplementary Material (online). Mean adenosine triphosphate (ATP) values and mean culture yield after 7 days (colony-forming units [CFU]/100 $\mathrm{mL}$ ) obtained after using different brushing techniques on soiled PTFE tubes are presented in Table 1. To our knowledge, this is the first study to compare the effectiveness of different types of brushes in manual cleaning of surrogate endoscope channels by means of microbiological culture and ATP values.

Our in vitro experiments revealed that, for soiled PTFE tubes, ATP values of samples cleaned with the Push\&Pull brush were significantly lower than those cleaned with the DCB and lower (but not significantly) than those cleaned with a PULL THRU brush. A literature search showed that there is no confirmed threshold for ATP value, so difficulties remain in interpreting this parameter.

There was no correlation between ATP measurements and culture results (Table 1). This result corresponds to the findings of Batailler et al, ${ }^{5}$ who concluded that ATP cannot be used as an alternative to microbiological tests for monitoring endoscope reprocessing. The Aquasnap Total test (Hygiena, Camarillo, CA) detects ATP from bacteria in addition to all other biological sources (organic residues) of ATP. Because CFU and relative light unit (RLU) values are determined using different test methods and measure different substances, we expect that RLU values do not consistently correlate with CFUs.

Culture results showed that mean yield from soiled PTFE tubes was lowest when the tube was cleaned with the Push\&Pull brush.
However, differences in mean CFU count did not reach statistical significance. The difference in CFU count can be presumed to not be clinically relevant either. Recovery in CFU/100 mL was calculated from the mean yield per brush type relative to the positive control, which did not undergo any reprocessing. These results are consistent with previous findings in literature that manual cleaning removes $>99 \%$ of the bioburden from the endoscope. ${ }^{3}$ Our study confirms the paramount importance of manual cleaning.

A fourth type of brush is a simple brush (Olympus). The design of the simple brush is basically a half DCB (with the brush part only on 1 side). Because the DCB had already showed inferior results to the 2 other brushes, we did not think it would be useful to include these in a further comparison.

In 2007, Charlton also compared the cleaning efficacy of different brushes. Efficacy was tested by applying a simulated blood soil to a lumen and comparing the weight difference before and after cleaning. In contrast to our study, which examined microbiological growth. Charlton concluded that the PULL THRU device was found to offer a consistently significant improvement in soil removal. ${ }^{6}$ He hypothesized this is because the wiper element design of the PULL THRU device provides a complete circumferential seal in the lumen channel. ${ }^{6}$

In Belgium, the authorities have issued guidelines for endoscope reprocessing. ${ }^{2}$ The guidelines state that the brushes used for manual cleaning are preferably single use, without other specifications. The European guidelines recommend brushing of all accessible channels using flexible, purpose-designed brushes. The size and type of cleaning brush must be matched appropriately to the size and type of endoscope channels to ensure contact with channel walls. In our study, PTFE tubes close to the actual size of endoscope channels were used. To ensure maximum effectiveness of cleaning and to avoid tissue carryover, the European Society of Gastrointestinal Endoscopy (ESGE) and the European Society of Gastroenterology and Endoscopy Nurses and Associates (ESGENA) recommend the use of single-use brushes because they have undamaged bristles without any tissue remnants from previous examinations. ${ }^{7}$ In the United States, the guidelines state to flush and brush all accessible channels with a brush appropriate for the size of the endoscope channel to remove all organic (eg, blood, tissue) 
and other residues. They also recommend that cleaning items should be disposable or thoroughly cleaned and disinfected or sterilized between uses. ${ }^{8}$

This study has several limitations. Our manually soiled PTFE tubes did not contain a biofilm in the sense of Michelle Alfa's definition. ${ }^{9}$ The "buildup biofilm" in endoscopes develops as a result of cyclical exposure to wet and dry phases during use and reprocessing. Because certain cleaning devices may compound the accretion of residual soil by causing surface abrasion or grooving of the lumen wall, additional research to address this issue could yield helpful insights. ${ }^{7}$ Furthermore, the conclusion of our study is not necessarily generalizable for several reasons. Experiments were only performed at a single hospital site by 1 person, and only endoscope models were used. A future larger study could include different types of endoscopes from different manufacturers in a real-life hospital setting.

Acknowledgments. Sofie Colman performed the calculations and wrote the manuscript. All authors discussed the results and commented on the manuscript.

Financial support. No financial support was provided relevant to this article.

Conflicts of interest. All authors report no conflicts of interest relevant to this article.

Supplementary material. To view supplementary material for this article, please visit https://doi.org/10.1017/ice.2021.170

\section{References}

1. Kovaleva J, Peters FT, van der Mei HC, Degener JE. Transmission of infection by flexible gastrointestinal endoscopy and bronchoscopy. Clin Microbiol Rev 2013;26:231-254.

2. Agentschap Zorg en Gezondheid. Eisenkader high level desinfectie van flexibele endoscopen in het ziekenhuis. 2014.

3. Garces E. Consequences of improper scope cleaning. Infection Control Today March 1, 2008. https://www.infectioncontroltoday.com/view/scopecleaning-and-repair

4. Cattoir L, Vanzieleghem T, Florin L, et al. Surveillance of endoscopes: comparison of different sampling techniques. Infect Control Hosp Epidemiol 2017;38:1062-1069.

5. Batailler P, Saviuc P, Picot-Gueraud R, Bosson JL, Mallaret MR. Usefulness of adenosinetriphosphate bioluminescence assay (ATPmetry) for monitoring the reprocessing of endoscopes. Infect Control Hosp Epidemiol 2015;36: 1437-1443.

6. Charlton TS. A comparison of the efficacy of lumen-cleaning devices for flexible gastrointestinal endoscopes. Aust Infect Control 2007;12:81-90.

7. Beilenhoff U, Neumann CS, Rey JF, Biering H, Blum R, Schmidt V. ESGEESGENA guideline for quality assurance in reprocessing: microbiological surveillance testing in endoscopy. Endoscopy 2007;39:175-181.

8. Petersen BT, Chennat J, Cohen J, et al. Multisociety guideline on reprocessing flexible gastrointestinal endoscopes: 2011. Gastrointest Endosc 2011;73: $1075-1084$.

9. Alfa MJ, Howie R. Modeling microbial survival in buildup biofilm for complex medical devices. BMC Infect Dis 2009;9:56-56.

\title{
Evaluation of Escherichia coli resistance to fluoroquinolones in men undergoing prostate procedures: Is it time to change preoperative prophylaxis?
}

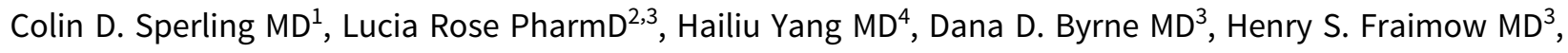 \\ Jeffrey J. Tomaszewski MD ${ }^{5}$ and Allen D. Seftel MD \\ ${ }^{1}$ Department of Urology, Hospital of the University of Pennsylvania, Philadelphia, Pennsylvania, ${ }^{2}$ Department of Pharmacy, Cooper University Hospital, Camden, \\ New Jersey, ${ }^{3}$ Division of Infectious Diseases, Department of Medicine, Cooper University Hospital, Camden, New Jersey, ${ }^{4}$ Gould Medical Group, Division of \\ Urology, Modesto, California, United States and ${ }^{5}$ Division of Urology, Department of Surgery, Cooper University Hospital, Camden, New Jersey
}

To the Editor-Urinary tract infections and prostatitis account for most postoperative infectious complications following prostate procedures, by direct inoculation of bacteria from skin or rectal mucosa into the prostate or urinary tract. Escherichia coli is the most common pathogen in $75 \%-90 \%$ of cases. ${ }^{1}$ Rates of sepsis from a urinary source are also rising, which may be secondary to increasing prevalence of antibiotic resistant uropathogens. ${ }^{2}$ Although the mechanisms leading to antibiotic resistance are complex, inappropriate utilization of antibiotics, particularly fluoroquinolones (FQs), has been shown to correlate with postprocedural infection risk due to ease of bacterial acquisition of resistance

\footnotetext{
Author for correspondence: Lucia Rose, E-mail: lucia.rose84@gmail.com; Rose-lucia@ cooperhealth.edu

Cite this article: Sperling CD, et al. (2022). Evaluation of Escherichia coli resistance to fluoroquinolones in men undergoing prostate procedures: Is it time to change preoperative prophylaxis?. Infection Control \& Hospital Epidemiology, 43: 1078-1080, https://doi.org/ $10.1017 /$ ice.2021.168
}

gene mutations. ${ }^{3}$ The Infectious Diseases Society of America (IDSA) now recommends avoiding empiric FQ use in genitourinary infections unless regional antibiogram data shows $<20 \%$ FQ resistance to $E$. coli.

Previous studies have demonstrated an increasing prevalence of FQ-resistant $E$. coli in the rectal vault of men undergoing transrectal ultrasound-guided prostate biopsy (TRUS-PBx). ${ }^{4}$ Despite these trends, the most current American Urological Association (AUA) best-practice statement, last amended in 2014, still recommends FQs as primary antimicrobial agents for preoperative prophylaxis for TRUS-PBx and transurethral procedures. ${ }^{5}$

Fluoroquinolone resistance to E. coli has reached $50 \%$ in some regions of the United States. ${ }^{6}$ As of 2018, our institution had been using ciprofloxacin preoperatively due to a lack of data supporting alternative agents. Our institution-wide antibiogram reports $\sim 30 \%$ FQ resistance to $E$. coli, but we were unsure of the generalizability to men undergoing prostate procedures. We aimed to evaluate FQ 